\title{
Effect of Maternal Iron Deficiency Anemia on Fetal Hemodynamics and \\ Pregnancy Outcome
}

\section{Abo Bakr Ibrahim Othman Omar ${ }^{1 *}$ MSc; Mohamed Taher Ismail ${ }^{1}$ MD; Bassem Ragab Abdel-Aziz ${ }^{1}$ MD}

*Corresponding Author:

Abo Bakr Ibrahim Othman Omar abobaakr92@gemil.com

\section{Received for publication November 19, 2020; Accepted january 3, 2021; Published online january 3, 2021.}

Copyright 2020 The Authors published by Al-Azhar University, Faculty of Medicine, Cairo, Egypt. All rights reserved. This an openaccess article distributed under the legal terms, where it is permissible to download and share the work provided it is properly cited. The work cannot be changed in anyway or used commercially.

doi: 10.21608/aimj.2021.50286.1356

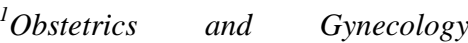
Department, Faculty of Medicine, Al-Azhar University,Cairo,Egypt.

\begin{abstract}
Background: In pregnancy, anaemia has detrimental impacts on maternal and fetal health. During pregnancy, chronic anemia may trigger glositis, stomatitis, alterations in the nails and skin, shortness of breath and heart failure in the mother. Obstetrical complications are also known, such as low birth weight babies, IUGR, elevated preterm delivery rate, and elevated perinatal deaths. Postpartum hemorrhage also aggravates the condition.

Aim of the work: To evaluate the impact on fetal hemodynamics of maternal iron deficiency anemia by Doppler parameters of umbilical and MCA, C/U ratio and to evaluate short term neonatal outcome by Apgar score and birth weight.

Patients and Methods: This cross sectional cohort study included 300 pregnant women suitable candidates who attended Al-Hussein and Sayed Galal Hospital for delivery and casualty department in the period between December 2019 October 2020

Results: Our results showed that oral and parenteral iron were superior than blood transfusion as regards the clinical and sonographic outcome (IUGR, preterm labor, NBW, APGAR score and Doppler indices) with a more rapid improvement using parenteral iron. However, those patients who received blood transfusion (group C) had a better elevation in hemoglobin levels compared to oral and parenteral iron.

Conclusion: Patients who received blood transfusion (group C) had a better elevation in hemoglobin levels however Patients who received oral and parenteral iron were superior than blood transfusion as regards the clinical and sonographic outcome .
\end{abstract}

Keywords: Appropriate ; gestational age ; iron deficiency ; anaemia, hemoglobin concentration.

Disclosure: The authors have no financial interest to declare in relation to the content of this article. The Article Processing Charge was paid for by the authors.

Authorship: All authors have a substantial contribution to the article.

\section{INTRODUCTION}

Haemoglobin concentration is utilized to assess the diagnosis and severity of anaemia in low resource environments, a marker which is regularly monitored using WHO-identified haemoglobin cutoffs. For pregnant women (females $\geq 15$ years of age), these thresholds are lower than for non-pregnant women $(11.0 \mathrm{~g} / \mathrm{dl} \mathrm{vs} 12.0 \mathrm{~g} / \mathrm{dl})$. Additional cutoffs are used to assess the severity of anaemia, with severe anaemia described as a haemoglobin level below $7.0 \mathrm{~g} / \mathrm{dl}$.

In general, anaemia is defined by a reduction in red blood cell count or less than the normal amount of hemoglobin. The disorder is defined by the predicted normal haemoglobin range in a population and is characterized as occurring in a person whose $\mathrm{Hb}$ has dropped below the threshold for a healthy population with the same demographic traits, which include age, gender and pregnancy status, with two standard deviations below the median. ${ }^{2}$

Anaemia of iron deficiency is characterized as reduced overall iron content of the body. Iron deficiency is characterized as a situation where iron 
despite no evidence of placental insufficiency, may be liable for fetal blood redistribution. ${ }^{5}$

The key focus of Doppler ultrasonography in obstetrics nowadays becomes to assess intrauterine growth-restricted fetuses following the introduction of the usage of umbilical artery and middle cerebral artery peak systolic velocity in high-risk pregnancies and pregnancies at risk of developing an anaemic fetus. Vasodilatation of the fetal middle cerebral artery takes place at the same time, resulting in the so-called 'brain sparing effect' (changes in compensatory flow or adaptation). Changes in middle cerebral artery Doppler indices have shown these physiological adaptations. ${ }^{6}$

While the etiology of IDA is multifaceted, it usually occurs if iron requirements are not fulfilled through absorption of iron for a number of causes. People with IDA could have insufficient iron intake attributable to inadequate dietary quantity and/or quality, impaired iron absorption or transport, or chronic blood loss attributable to secondary illness. ${ }^{2}$

\section{PATIENTS AND METHODS}

There were three groups of pregnant women: Group A (100 patients): mild anaemia patients (concentration of $\mathrm{Hb}$ : 9.0-10.9 gldl). Group B (100 patients): moderate anaemia patients (concentration of $\mathrm{Hb}$ : 7.0-8.9 gldl). Group C (100 patients): Severe anaemia patients (concentration of $\mathrm{Hb}:<7.0 \mathrm{~g} \backslash \mathrm{dl}$ ).

Inclusion criteria: Age: 20-35 years old. Singleton pregnancy. Living fetus.

Exclusion criteria: Patients of chronic disease or medical condition other than iron deficiency anaemia, such as chronic high blood pressure, D.M. or chronic blood loss e.g.; peptic ulcer. History of frequent perinatal mortality, recent transfusions of blood or anaemia with vitamin deficiency. Patients with pregnancy associated disorders as: preeclampsia, gestational diabetes or placenta previa (recurrent vaginal bleeding).

The outcome: Maternal: Hemoglobin levels. Serum Ferritin level. Amniotic fluid index (AFI). Umbilical artery resistance index (UMRI). Middle cerebral artery/Umbilical artery resistance index ratio $(\mathrm{C} / \mathrm{U})$. At delivery, neonates were subjected to: APGAR scoring at five minutes (pathological if $<7$ ). Birth weight. Admission to NICU.

Statistical analysis:

The reported data was analyzed using version 20.0 of the statistical package for social sciences (SPSS Inc., Chicago, Illinois, USA). The mean \pm standard deviation (SD) was represented as quantitative data. The frequency and percentage were represented as qualitative data.

The following tests were done: A one-way analysis of variance (ANOVA) where there are more than two means to compare. Post Hoc test: For multiple comparisons among various variables, Least Significant Difference (LSD) was used. Kruskall Wallis test: non-parametric data for multiple-group comparisons. In order to compare ratios among qualitative parameters, the Chi-square (x2) significance test has been used. The confidence interval was set at $95 \%$ and the agreed error margin became set at $5 \%$.

RESULTS

\begin{tabular}{|c|c|c|c|c|c|}
\hline $\begin{array}{c}\text { Clinical } \\
\text { Criteria }\end{array}$ & $\begin{array}{c}\text { Group (A) } \\
(\mathbf{n}=\mathbf{1 0 0})\end{array}$ & $\begin{array}{c}\text { Group (B) } \\
(\mathbf{n}=\mathbf{1 0 0})\end{array}$ & $\begin{array}{c}\text { Group (C) } \\
(\mathbf{n}=\mathbf{1 0 0})\end{array}$ & $\mathbf{F}$ & $\begin{array}{c}\text { p- } \\
\text { value }\end{array}$ \\
\hline \hline $\begin{array}{c}\text { Age } \\
\text { (years) }\end{array}$ & $30.10 \pm 2.02$ & $30.10 \pm 0.51$ & $30.30 \pm 3.03$ & 1.485 & 0.107 \\
\hline Parity\# & $2(3)$ & $2(4)$ & $3(3)$ & 1.113 & 0.235 \\
\hline $\begin{array}{c}\text { GA. by on } \\
\text { admission } \\
\text { (weeks) }\end{array}$ & $33.14 \pm 2.02$ & $34.71 \pm 2.83$ & $32.42 \pm 2.93$ & 0.196 & 0.569 \\
\hline $\begin{array}{c}\text { GA. by } \\
\text { ultrasound } \\
\text { on } \\
\text { admission } \\
\text { (weeks) }\end{array}$ & $33.14 \pm 0.61$ & $32.85 \pm 2.22$ & $30.57 \pm 1.92$ & 1.113 & 0.134 \\
\hline $\begin{array}{c}\text { GA. by at } \\
\text { delivery } \\
\text { (weeks) }\end{array}$ & $39.57 \pm 0.51$ & $38.14 \pm 0.30$ & $36.85 \pm 0.40$ & 1.355 & 0.116 \\
\hline
\end{tabular}

\#Median (IQR) Interquartile range

Using: One Way Analysis of variance; \#Kruskal

Wallis-H test; p-value $>0.05 \mathrm{NS}$

Table 1: Comparison among hemoglobin group according to clinical criteria.

\begin{tabular}{|c|c|c|c|c|c|}
\hline & $\begin{array}{c}\text { Group (A) } \\
(n=100)\end{array}$ & $\begin{array}{c}\text { Group (B) } \\
(n=100)\end{array}$ & $\begin{array}{c}\text { Group (C) } \\
(n=100)\end{array}$ & $\mathbf{F}$ & p-value \\
\hline \multicolumn{6}{|l|}{$\mathrm{Hb}(\mathrm{g} \%)$} \\
\hline On admission & $9.92 \pm 0.61$ & $8.55 \pm 0.40^{\prime}$ & $6.87 \pm 0.20^{77}$ & 4.422 & $<0.001$ ** \\
\hline At 10 days later & $10.67 \pm 0.20$ & $10.10 \pm 0.51$ & $9.70 \pm 0.61$ & 1.525 & 0.184 \\
\hline At delivery & $10.61 \pm 0.81$ & $10.50 \pm 0.40$ & $10.16 \pm 1.11^{17}$ & 3.047 & $0.029 *$ \\
\hline \multicolumn{6}{|l|}{$\begin{array}{l}\text { Serum ferritin } \\
(\mathrm{ng} / \mathrm{ml})\end{array}$} \\
\hline On admission & $9.60 \pm 2.12$ & $8.79 \pm 2.93^{\dagger}$ & $6.67 \pm 2.22^{\gamma t}$ & 4.806 & $<0.001 * *$ \\
\hline At days later & $10.20 \pm 2.22$ & $10.00 \pm 3.13$ & $9.09 \pm 2.73$ & 0.801 & 0.223 \\
\hline At delivery & $20.10 \pm 3.64$ & $18.08 \pm 3.13$ & $15.45 \pm 2.83^{\dagger}$ & 1.852 & $0.037 *$ \\
\hline \multicolumn{6}{|l|}{ AFI (cm) } \\
\hline On admission & $12.16 \pm 1.11$ & $13.37 \pm 0.91$ & $9.09 \pm 2.02^{\gamma t}$ & 2.636 & $0.013^{*}$ \\
\hline At days later & $12.02 \pm 1.01$ & $13.94 \pm 1.31^{\dagger}$ & $13.13 \pm 2.12^{\gamma}$ & 2.492 & $0.009 *$ \\
\hline At delivery & $9.90 \pm 2.12$ & $10.91 \pm 2.02^{\dagger}$ & $12.37 \pm 2.02^{\dagger t}$ & 2.707 & $0.027 *$ \\
\hline \multicolumn{6}{|l|}{$\begin{array}{c}\text { Umbilical } \\
\text { artery (RI) }\end{array}$} \\
\hline On admission & $0.69 \pm 0.06$ & $0.69 \pm 0.05$ & $0.70 \pm 0.03$ & 0.303 & 0.472 \\
\hline At days later & $0.69 \pm 0.06$ & $0.69 \pm 0.05$ & $0.68 \pm 0.02^{\gamma / 7}$ & 2.510 & $0.042 *$ \\
\hline At delivery & $0.68 \pm 0.03$ & $0.71 \pm 0.04$ & $0.66 \pm 0.06^{t}$ & 3.352 & $0.014 *$ \\
\hline \multicolumn{6}{|l|}{$\begin{array}{c}\text { MCA/Umbilical } \\
\text { artery ratio }\end{array}$} \\
\hline On admission & $1.11 \pm 0.10$ & $1.05 \pm 0.02$ & $0.86 \pm 0.02$ & 0.696 & 0.345 \\
\hline At days later & $1.11 \pm 0.01$ & $1.10 \pm 0.01$ & $1.21 \pm 0.02$ & 0.994 & 0.166 \\
\hline At delivery & $1.08 \pm 0.07$ & $1.09 \pm 0.07$ & $1.16 \pm 0.02$ & 1.282 & 0.154 \\
\hline
\end{tabular}

Using: One Way Analysis of variance

Post HOC test, LSD: $\uparrow$ : significant difference with group $\mathrm{A} ; \sharp$ : significant difference with group $\mathrm{B}$ p-value $>0.05 \mathrm{NS}$; *p-value $<0.05 \mathrm{~S}$; **p-value $<0.001 \mathrm{HS}$

Using: One Way Analysis of variance; $p$-value $>0.05$ NS

Table 2: Comparison between hemoglobin group according to mean $\mathrm{Hb}$, serum ferritin (ng/ml), AFI, umbilical artery RI, MCA/umbilical artery ratio on admission, at 10 days and at delivery.
Obstetrics and Gynecology 


\begin{tabular}{|c|c|c|c|c|c|}
\hline & $\begin{array}{c}\text { Group } \\
(\mathbf{A}) \\
(\mathrm{n}=100)\end{array}$ & $\begin{array}{c}\text { Group } \\
(B) \\
(n=100)\end{array}$ & $\begin{array}{c}\text { Group (C) } \\
\quad(\mathbf{n}=\mathbf{1 0 0})\end{array}$ & $x^{2}$ & p-value \\
\hline \multicolumn{6}{|l|}{ IUGR } \\
\hline No & $\begin{array}{c}100 \\
(100 \%)\end{array}$ & $97(97 \%)$ & $94(94 \%)$ & \multirow{2}{*}{$\begin{array}{c}6.18 \\
6\end{array}$} & \multirow[t]{2}{*}{$0.045^{*}$} \\
\hline Yes & $0(0 \%)$ & $3(3 \%)$ & $6(6 \%)$ & & \\
\hline \multicolumn{6}{|l|}{ PTL } \\
\hline No & $98(98 \%)$ & $96(96 \%)$ & $90(90 \%)$ & \multirow{2}{*}{$\begin{array}{c}6.86 \\
6 \\
\end{array}$} & \multirow{2}{*}{$0.032 *$} \\
\hline Yes & $2(2 \%)$ & $4(4 \%)$ & $10(10 \%)$ & & \\
\hline \multicolumn{6}{|l|}{$\begin{array}{c}\text { Neonatal } \\
\text { birth } \\
\text { weight in } \\
(\mathrm{Kg})\end{array}$} \\
\hline Mean \pm SD & $\begin{array}{c}3.46 \pm 0.2 \\
0 \\
\end{array}$ & $\begin{array}{c}2.94 \pm 0.02 \\
t\end{array}$ & $2.72 \pm 0.07^{\dagger}$ & $\begin{array}{c}3.98 \\
8 \\
\end{array}$ & $0.005^{*}$ \\
\hline \multicolumn{6}{|l|}{$\begin{array}{c}\text { Mean } \\
\text { APGAR } \\
\text { score }\end{array}$} \\
\hline $\begin{array}{c}\text { Mean } \pm \mathbf{S} \\
\text { D } \\
\end{array}$ & $\begin{array}{c}8.79 \pm 0.2 \\
0 \\
\end{array}$ & $8.59 \pm 0.02$ & $\begin{array}{c}7.58 \pm 0.07^{\dagger} \\
\ddagger\end{array}$ & $\begin{array}{c}3.08 \\
6 \\
\end{array}$ & $\begin{array}{c}<0.001 * \\
*\end{array}$ \\
\hline \multicolumn{6}{|l|}{$\begin{array}{c}\text { NICU } \\
\text { admissio } \\
n\end{array}$} \\
\hline No & $\begin{array}{c}100 \\
(100 \%) \\
\end{array}$ & $98(98 \%)$ & $95(95 \%)$ & $\begin{array}{c}5.55 \\
8 \\
\end{array}$ & 0.062 \\
\hline Yes & $0(0 \%)$ & $2(2 \%)$ & $5(5 \%)$ & & \\
\hline
\end{tabular}

Using: Chi-square test; *p-value $<0.05 \mathrm{~S}$

Using: One Way Analysis of variance; **p-value $<0.001$ HS

Post HOC test, LSD: $\uparrow$ : significant difference with group A; $\$$ : significant difference with group B

Table 3: Comparison between hemoglobin group according to IUGR, preterm labor, neonatal birth weight $(\mathrm{kg})$, APGAR score and NICU admission.

\section{DISCUSSION}

Anemia during pregnancy is defined according to WHO guidelines to be hemoglobin level below $11 \mathrm{~g} / \mathrm{dl}$. Mild anemia is defined as a hemoglobin value between $10-10.9 \mathrm{~g} / \mathrm{dl}$, hemoglobin concentration between $7-9.9 \mathrm{~g} / \mathrm{dl}$ indicates moderate anemia and severe anemia has been identified as a concentration of hemoglobin $<7 \mathrm{~g} / \mathrm{dl}$. Iron supplementation decreases the prevalence of maternal anemia at delivery. ${ }^{7}$

In this research, there was no statistically substantial variation in the mean age and parity in between mild, moderate and severe iron deficiency anemic pregnant females.

This agrees with result of Judith ${ }^{8}$ who suggests that maternal age and parity were independently associated with maternal anemia.

This is also consistent with the findings of Yadav et al. ${ }^{7}$ in which gravidity was not a significant predictor of $\mathrm{Hb}$ concentration.

This result was not in agreement with Upadhyay et al. ${ }^{9}$ study that showed a significant relationship between parity and severity of anemia.
In this study, as regards the hemoglobin levels and serum ferritin levels, it was found that the major impact of treatment was on the patients in group (C) [severe anemia] as the hemoglobin concentration was elevated by about 3.5 $\mathrm{g} \%$ from admission to time of labor. This shows the impact of blood transfusion on improving the blood hemoglobin status. Yet, the hemoglobin levels in moderate anemia were also elevated by about $2.0 \mathrm{~g} \%$, meanwhile in mild anemia group an elevation by about $1 \mathrm{~g} \%$.

At time of labor, a statistically substantial variation was found among group (A) [mild anemia] and group (B) [moderate anemia]. This result spotlights the fact that both oral iron supplementation and parenteral iron transfusion had almost a similar impact on hemoglobin level and serum ferritin level on the long run.

This result agrees with that reported by Khalafallah et al. ${ }^{10}$ that: intravenous plus oral iron was only superior to oral iron as determined by a rise in the level of hemoglobin and a rise in the mean level of serum ferritin.

Also in accordance with that reported by Shi et al. ${ }^{11}$ that: intravenous iron sucrose became correlated with less adverse outcomes and was more successful than regular oral iron treatment in pregnant women who were unable to handle the adverse impacts of oral therapy or needed a rapid substitution of iron stores.

As for the AFI, in this study there is no significant effect was noticed in the 3 groups but a potential benefit might be the prevention of development of oligohydramnios as pregnancy advances especially in group (C) [severe anemia].

In this study, data regarding the umbilical artery RI showed a statistically substantial variation among group (A) [mild anemia] and the other 2 groups after 10 days of treatment with a higher RI in group (A); this might be attributed to the non effectiveness of oral iron supplementation on short-term therapy. On the other hand, at the time of delivery the 3 groups showed improvement in the umbilical RI but still group (C) [severe anemia] had the best chance of improved RI. This result also points out to the effectiveness of blood transfusion on the long-term outcome.

In this study, as for the $\mathrm{ClU}$ ratio, in Group B\&C [moderate and severe anemia], which confirms that the fetus had to adapt by increasing the redistribution of its blood flow to the brain. The rise in both the cerebral index and $\mathrm{C} / \mathrm{U}$ ratio following maternal red blood cell transfusion and parenteral iron transfusion established this adaptation. The rise in posttransfusion cerebral resistance without a major improvement in umbilical resistance suggests that maternal anaemia does not generate placental dysfunction and that two units of red blood transfusion to the patient or intravenous iron will rapidly restore the situation. The $\mathrm{C} / \mathrm{U}$ values were within the normal range in Group (A) [mild anaemia], that implies that the blood flow distribution among the brain and placenta was normal despite the slightly lower maternal haemoglobin content relative to normal.

There is an increased incidence of blood flow in the umbilical and fetal renal arteries with severe 
intrauterine growth restriction correlated with hypoxemia. Vasodilatation of the fetal middle cerebral artery takes place at the same time, resulting in the so-called 'brain sparing effect' (changes in compensatory flow or adaptation). Changes in middle cerebral artery Doppler indices have shown these physiological adaptations. ${ }^{12}$

In this study, as regards the incidence of preterm labor, $5.3 \%$ of the total number of cases were recorded (16 cases), most of which were in group (C) (10 cases) however, the difference was statistically significant between the three groups.

This comes in accordance with Watkins et al. ${ }^{13}$ in a case-control study, anaemia was confirmed to be positively correlated with premature delivery at any time during the second trimester, but it did not account for the significant ethnic disparity in preterm delivery.

Engelhardt et al. ${ }^{14}$ studies on risk factors for preterm delivery in a stable cohort investigated whether risk factors varied among preterm delivery subgroups and reported that there was no correlation among anemia and preterm delivery. They concluded that the lack of correlation is compatible with the finding that most of the triggers of preterm delivery are still unexplained by other investigators.

In this study, Neonatal birth weight (NBW) and prevalence of intrauterine growth restriction (IUGR) were strongly correlated. Only $3 \%$ of the total number of cases had IUGR ( 9 cases); most of which were in group (C) (6 cases). All neonatal birth weights were within normal range despite the very few cases of IUGR; and group (A) [mild anemia] showed the highest neonatal birth weight when compared to the other 2 groups.

This comes in accordance with Grzeszczak et al. ${ }^{15}$ who reported that maternal hemoglobin level had a significant positive correlation with the neonatal birth weight.

In this study, the neonatal well being measured by the APGAR score at five min was assessed. All scores for APGAR became normal (>7 at $5 \mathrm{~min}$ ) but still group (C) [severe anemia] had lower fetal APGAR scores most of which were related to transient tachypnea of the newborn (TTN) that resolved in the majority of cases.

In some research, a correlation was identified among maternal anaemia and lower Apgar scores for infants. Higher maternal haemoglobin levels were associated with improved Apgar scores and a lower risk of birth asphyxia for 102 Indian women in the first stage of childbirth. Apgar scores were substantially greater in infants whose mothers received iron when pregnant women were treated with iron or placebo in Niger. ${ }^{16}$

Also agrees with Amin et al. ${ }^{17}$ who reported that severe anaemia due to iron deficiency in pregnant women is associated with poor pregnancy outcome include increased risk of intra uterine growth retardation and preterm labor.

Also Upadhyay et al. ${ }^{9}$ showed a significant casual relationship between maternal severe iron deficiency anemia and preterm birth and IUGR compared with moderate iron deficiency anemic pregnant females.
But according to Teng et al. ${ }^{18}$ the association among third trimester anaemia and poor obstetric outcomes during pregnancy seems to be not strong.

Cao and O'Brien ${ }^{19}$ reported that severe iron deficiency anemia with hemoglobin levels lower than $6 \mathrm{gm} / \mathrm{dl}$ is correlated with poor pregnancy outcomes and affects maternal wellbeing during pregnancy. However a mild to moderate deficiency of iron does not seem to have a major impact on the fetal and maternal outcome.

\section{CONCLUSION}

Patients who received blood transfusion (group C) had a better elevation in hemoglobin levels however Patients who received oral and parenteral iron were superior than blood transfusion as regards the clinical and sonographic outcome (IUGR,Preterm labor,NBW,APGAR scor and dopler indices (Umbilical artery resistance index (UMRI), Middle cerebral artery/Umbilical artery resistance index ratio $(\mathrm{C} / \mathrm{U})$, Middle cerebral artery resistance index.

\section{REFERENCES}

1. RCOG guidelines. New $S$, Wirth $M$. Anaemia, pregnancy, and maternal mortality: the problem with globally standardised haemoglobin cutoffs. BJOG. 2015; 122:166-9.

2. Nakade M, Jungari ML, Ambad R and Dhingra G. Status of Vitamins and Minerals in Pregnancy: Still A Point of Concern in Central India. Int J Cur Res Rev. 2020; 12(14): 1-18.

3. Charles CV. Iron Deficiency Anemia: A Public Health Problem of Global Proportions, Public Health - Methodology, Environmental and Systems Issues, Prof. Jay Maddock (Ed.), ISBN: 978-953-51-0641-8; 2012.

4. Akhter S, Momen M, Rahman M, Parveen T and Karim RK. Effect of maternal anemia on fetal outcome title: Mymensingh medical journal: MMJ: ISO Abbreviation: Mymensingh Med J publication Date. 2010: 19 ISSN: 1022-4742.

5. Breymann C, Milman $N$, Mezzacasa A, Bernard $R$ and Dudenhausen J. Ferric carboxymaltose vs. oral iron in the treatment of pregnant women with iron deficiency anemia: an international, open-label, randomized controlled trial (FER-ASAP). Journal of perinatal medicine, 2017; 45(4): 443-53.

6. Rial-Crestelo M, Martinez-Portilla RJ, Cancemi A, Caradeux J, Fernandez L, Peguero A, Gratacos E and Figueras F. Added value of cerebro-placental ratio and uterine artery Doppler at routine third trimester screening as a predictor of SGA and FGR in nonselected pregnancies. The Journal of Maternal-Fetal \& Neonatal Medicine. 2019; 32(15):2554-60.

7. Yadav K, Arjun MC, Jacob OM, Kant S, Ahamed F and Ramaswamy G. Comparison of different doses of daily iron supplementation for anemia prophylaxis in pregnancy: A systematic review. Journal of Family Medicine and Primary Care. 2020; 9(3):1308.
Obstetrics and Gynecology 
8. Judith A : Journal of South Asian Federation of Obstetrics and Gynecology, 2012 :4 (1):64-70.

9. Upadhyay C, Bulusu R and Shah N. A prospective study on prevalence and management of anaemia in pregnancy with perinatal outcome. Journal of Evolution of Medical and Dental Sciences. 2013; 2(35):6664-73.

10. Khalafallah A, Dennis A, Bates G and Robertson IK A prospective randomized, controlled trial of intravenous versus oral iron for moderate iron deficiency anemia of pregnancy. J Intern Med. 2010; 268 (3):286-95.

11. Shi Q, Leng W and Wazir R. Intravenous Iron Sucrose versus Oral Iron in the Treatment of Pregnancy with Iron Deficiency Anaemia. Gynecol Obstet Invest. 2015; 80 (3):170-8.

12. Stefopoulou M, Johnson J, Wilsgaard T, Lindgren $P$, Herling L, Kiserud T and Acharya G. Volume blood flow-based indices of fetal brain sparing in the second half of pregnancy: A longitudinal study. Acta Obstetricia et Gynecologica Scandinavica. 2020; 1(2): 1-15.

13. Watkins VY, Frolova AI, Stout MJ, Carter EB, Macones GA, Cahill AG and Raghuraman N. The relationship between maternal anemia and umbilical cord oxygen content at delivery. American Journal of Obstetrics \& Gynecology MFM. 2020; 100270.
14. Engelhardt KA, Hisle-Gorman E, Gorman GH and Dobson NR. Lower Preterm Birth Rates but Persistent Racial Disparities in an Open-Access Health Care System. Military medicine, 2018; 183(910): 570.

15. Grzeszczak K, Kwiatkowski S and Kosik-Bogacka D. The Role of $\mathrm{Fe}, \mathrm{Zn}$, and $\mathrm{Cu}$ in Pregnancy. Biomolecules. 2020; 10(8):1176.

16. Schulze KJ, Gernand AD, Khan AZ, Wu LS, Mehra S, Shaikh S, Ali H, Shamim AA, Sungpuag P, Udomkesmalee $\mathrm{E}$ and Labrique AB. Newborn micronutrient status biomarkers in a clusterrandomized trial of antenatal multiple micronutrient compared with iron folic acid supplementation in rural Bangladesh. The American Journal of Clinical Nutrition. 2020; 2(3): 1-18.

17. Amin ME, Ali ME, Mohamed AH, Sanad SA, Alghobary HA and Fahmy YA. Effect of Maternal Iron Deficiency Anemia on Fetal Hemodynamics and Neonatal Outcome. Indian Journal of Public Health Research \& Development, 2020; 11(4).

18. Teng X, Shan Z, Li C, Yu X, Mao J, Wang W, Xie $\mathrm{X}$, Du J, Zhang $\mathrm{S}$, Gao $\mathrm{Z}$ and Zhang $\mathrm{X}$. Iron Deficiency May Predict Greater Risk for Hypothyroxinemia: A Retrospective Cohort Study of Pregnant Women in China. Thyroid. 2018; 24(8): 213.

19. Cao $\mathrm{C}$ and O'Brien KO. Pregnancy and iron homeostasis: an update. Nutrition reviews. 2013; 71(1):35-51 